\title{
Para uma avaliação das práticas literácitas em leitura e escrita no jardim de infância
}

\section{Assessment of literacy practices in reading and writing at kindergarten}

\author{
Maria Cristina Vieira da Silva \\ ESE de Paula Frassinetti - CIPAF/ CIEC da Universidade do Minho
}

\begin{abstract}
Resumo
O desenvolvimento da literacia emergente permite a crianças em idade pré-escolar construir hipóteses acerca da funcionalidade e aspetos conceptuais da linguagem escrita (Ferreiro \& Teberosky, 1986). Três décadas passadas sobre esta obra pioneira, considerámos oportuno aferir como as práticas pedagógicas no domínio da leitura e escrita são informadas pela teoria. Para o efeito, aplicámos uma versão adaptada da grelha de observação dessas práticas, de Alves Martins \& Santos (2005), em doze salas de jardim de infância de educadores cooperantes. Os resultados mostram que as práticas observadas denotam ausência de intencionalidade educativa e falta de sistematicidade em algumas atividades.

Palavras chave: Literacia emergente, jardim de infância; avaliação.
\end{abstract}

\begin{abstract}
The development of emerging literacy allows pre-school children to construct hypotheses about the functionality and conceptual aspects of written language (Ferreiro \& Teberosky, 1986). Three decades after the publication of this pioneering work, we considered it opportune to gauge how pedagogical practices in the field of reading and writing are currently informed by theory. To that end, we applied an adapted version of the grid for observing these practices, by Alves Martins \& Santos (2005), in twelve kindergartens of cooperating educators. The results show that the observed practices denote lack of educational intentionality and lack of systematicity in some activities. Keywords: Emergent literacy, kindergarten, assessement.
\end{abstract}

O desenvolvimento da literacia em idade pré-escolar configura-se como uma oportunidade para que as crianças construam hipóteses e reelaborem conceções acerca da funcionalidade e aspetos conceptuais da linguagem escrita, competências estas determinantes para o sucesso posterior na aprendizagem da leitura e da escrita. De facto, à construção destes conceitos e funções subjazem pressupostos teóricos que enquadram o desenvolvimento literácito: este inicia-se precocemente e desenvolve-se no quotidiano da criança, mediante participação em atividades com uma intencionalidade pedagógica em que ler e escrever estão interrelacionados.

Desde o trabalho pioneiro de Ferreiro \& Teberosky (1986), muitos têm sido os trabalhos que têm vindo a mostrar a importância de práticas literácitas intencionais no domínio da leitura e da escrita no jardim de infância. A identificação de etapas conceptuais na apropriação da linguagem escrita (Alves Martins, 1996) veio alertar para a necessidade de criar oportunidades para a criança interagir, manipular, explorar e utilizar, com diferentes finalidades, a linguagem escrita (Mata, 2008) em atividades que ocorrem naturalmente nas rotinas quotidianas, mas cujo impacto e importância são desvalorizados. Dada a importância do jardim de infância em todo este processo, interessa compreender as características destes contextos, os modos como a criança neles interagem com a leitura e escrita e as práticas pedagógicas dos educadores. Algumas investigações sobre o jardim de infância procuraram analisar a relação entre as práticas de literacia desenvolvidas, os materiais existentes ou ainda as conceções dos educadores sobre a linguagem escrita (Santos \& Alves Martins, 2014; Fernandes, 2005) e os conhecimentos das crianças (Alves Martins, 2007). Neste último estudo, realizado em Portugal com 16 educadores de infância, Alves Martins (2007) identificou diferenças significativas nas conceptualizações e na perceção de funcionalidade das crianças, consoante os seus educadores integravam e abordavam de forma diferenciada (em termos de diversidade e frequência) a linguagem escrita nas suas práticas pedagógicas. Já Fernandes (2005) assinala que a apropriação do conceito de promoção de literacia emergente pelos educadores, envolvendo medidas organizadas e intencionais, parece ser pouco consensual.

Volvidas mais de duas décadas desde os trabalhos pioneiros desenvolvidos por Ferreiro e Teberosky (Ferreiro \& Teberosky, 1986; Ferreiro, 1990) até à incorporação de alguns destes princípios nas Metas de Aprendizagem para a Educação Pré-escolar (2010 e nas Orientações Curriculares para a Educação Pré-Escolar (2016), considerámos oportuno aferir de que forma os educadores de infância integravam, nas suas práticas pedagógicas no domínio da leitura e da escrita, estes mesmos princípios.

\section{Método}

Para o efeito, aplicámos uma versão adaptada da grelha de observação das práticas no domínio da leitura e escrita, de Alves Martins \& Santos (2005), em seis salas de jardim de infância com crianças de três a cinco anos 
onde mestrandas de uma instituição de Ensino Superior (IES) se encontravam a estagiar. Três objetivos estão subjacentes a este trabalho: conhecer modos de gestão da sala e práticas literácitas dos educadores cooperantes; identificar áreas críticas nos contextos de PES a salvaguardar em termos de necessidades formativas das mestrandas; diagnosticar áreas fortes e fracas da prática das educadoras cooperantes a salvaguardar em termos da oferta de formação contínua.

\section{Instrumento e procedimento}

O instrumento de recolha de dados utilizado foi uma versão adaptada da grelha de observação das práticas no domínio da leitura e da escrita, de Alves Martins \& Santos (2005), constituída por cinquenta e cinco itens relativos ao projeto pedagógico, à organização e gestão do espaço físico da sala e da rotina diária e ainda às práticas de leitura e de escrita. A seleção deste instrumento de observação e avaliação da prática pedagógica no domínio da leitura e da escrita em contexto de JI prende-se com o facto de este ser um dispositivo que, permitindo um olhar e uma reflexão mais sistemáticos sobre as práticas em torno da linguagem escrita, foi construido com propósitos que se aproximavam dos nossos objetivos, nomeadamente avaliar se no JI se promove a leitura e escrita por parte das crianças, seja no espaço da sala ou na organização das áreas, bem como aferir se o educador, nas suas práticas, promove o domínio da leitura e da escrita no âmbito das atividades e objetivos do projeto pedagógico. Constituida por um total de 60 itens, a grelha está organizada em três grandes domínios: projeto pedagógico (3 itens), organização e gestão do espaço físico da sala e da rotina diária (17 itens) e, por fim, práticas de leitura e de escrita (35 itens). Segundo Alves Martins \& Santos (2005:61), os três primeiros itens têm por objetivo "perceber se o projecto pedagógico inclui objectivos para o domínio da linguagem oral e da linguagem escrita, qual a regularidade das planificações efectuadas e se estas incluem actividades, estratégias e recursos específicos para o trabalho sobre a linguagem escrita". Já a dimensão da grelha relativa à organização e gestão do espaço físico da sala e da rotina diária tem por objetivo identificar "a forma como a área da biblioteca e as outras áreas de trabalho estão organizadas, que tipos de materiais de leitura e de escrita existem e de que forma são utilizados. Destinam-se, igualmente, a observar de que forma a rotina diária contempla actividades que apelam à leitura e à escrita." (idem:61) Por fim, os "itens que constituem a terceira parte desta grelha destinam-se a observar a regularidade com que diversas actividades relacionadas com a linguagem escrita são desenvolvidas pelos educadores, assim como de que forma são apoiadas as tentativas de leitura e de escrita das crianças.” (idem, 61).

\section{Participantes}

A recolha de dados decorreu entre março e junho de 2016 e foi levada a cabo por intermédio de estagiárias do mestrado em Educação de Infância, em salas de JI de instituições cooperantes (públicas e privadas) de uma IES. A amostra de conveniência foi fixada em doze salas de JI (quatro salas de três anos, quatro salas de quatro anos e quatro salas de cinco anos), para efeitos deste estudo exploratório. Ao selecionarmos um igual número de salas observadas com crianças de diferentes idades, foi nosso objetivo verificar de que forma as práticas pedagógicas promotoras da Leitura e Escrita eram diferenciadas nas salas em função do fator idade.

\section{Resultados e sua discussão}

No que respeita à primeira dimensão observada, relativa ao Projeto Pedagógico, pudemos observar que onze das doze salas observadas dispõem de projeto pedagógico (PP) escrito, sendo que todos eles incluem objetivos para a linguagem oral mas não para a linguagem escrita (apenas sete das onze registavam tal intencionalidade). No caso dos PP que incluíam planificações específicas (ou seja, em oito dos onze PP existentes), todas estas tinham periodicidade semanal, com objetivos especificados para o desenvolvimento da linguagem oral na totalidade dos oito casos e para o desenvolvimento da linguagem escrita omissos apenas em três salas de três anos.

Mais do que a documentação que formaliza as intenções pedagógicas, a organização do espaço físico e da rotina diária podem dar-nos pistas para aferirmos as práticas pedagógicas em torno da literacia emergente.

A este nível, foi-nos possível observar que a área da biblioteca se encontrava presente em todas as salas, ainda que com distintas dimensões e localizações. No caso das salas quer de três, quer de quatro anos, as reduzidas dimensões do espaço que ocupa e a ausência de luz natural são indicadores de não ser esta uma área privilegiada. Já no que respeita às quatro salas de cinco anos observadas, esta área ganha uma dimensão considerável, localizando-se, em três delas, na proximidade da área de escrita e dispondo de luz natural, o que promove a possibilidade de integração de atividade de Leitura e de Escrita e facilita às crianças a sua utilização independente.

Regra geral, neste espaço, as salas têm um acervo muito limitado a livros de histórias ou temáticos, sendo que outros suportes, como revistas ou enciclopédias e dicionários ilustrados são pouco frequentes ou mesmo inexistentes. Por seu turno, os recursos existentes nesta área (maioritariamente livros), sendo de fácil acesso, têm o seu manuseamento restrito ao espaço da biblioteca, à exceção de três das doze salas observadas. $\mathrm{O}$ facto de não ser permitido, naquelas salas, que as crianças possam levar os materiais de leitura para qualquer outra área, para além do efeito inibidor no seu uso, condiciona a perceção (que seria importante as crianças desenvolverem) quanto às diversas funcionalidades que os diferentes materiais escritos podem desempenhar. Foi ainda possível apurar que a área da biblioteca é utilizada sobretudo por livre iniciativa das crianças e pouco frequentemente sugerida ou proposta pelo educador para a realização de atividades específicas.

Para além da área da biblioteca, foi ainda assinalada a existência de materiais de escrita e leitura na área com a mesma designação ou ainda na área de pesquisa e escrita, bem como na área de plástica, nomeadamente placas com a identificação do nome de cada criança, dicionários de 
letras, ímans de letras, lápis e marcadores, folhas em branco, etiquetas e folhas de registo das atividades pelas educadoras.

É ainda de registar, em três das quatro salas observadas, a existência da área do computador, a qual se situava, no entanto, longe quer da área da biblioteca, quer da área da escrita, o que indicia que, como se veio a confirmar pela análise das práticas observadas, este recurso não é usado para fins relacionados com a promoção da leitura e da escrita. O uso de computador, tablet ou mesmo máquina de escrever foi apenas reportado em metade das salas observadas (em duas salas de três anos; numa sala de quatro anos e em três salas de cinco anos), sendo que o uso decorre da iniciativa da criança apenas em três salas de cinco anos. Nas restantes salas de quatro e cinco anos que dispõem deste recurso, a sua utilização só muito ocasionalmente é sugerida pela educadora, aquando da proposta de uma atividade específica.

No que diz respeito à incorporação das produções escritas das crianças para efeitos da sua utilização e melhor assimilação das funções da linguagem escrita, pelas próprias crianças, é de assinalar que todas as salas dispõem de locais próprios para afixar registos escritos, estando a maioria (em dez das doze salas observadas) ao alcance visual das crianças e sendo substituídas por registos mais recentes com uma periodicidade semanal ou quinzenal. No entanto, e apesar de estes registos se encontrarem afixados ao nível dos olhos ou inferior em dez das salas observadas, os mesmos registos eram usados espontaneamente pelas crianças poucas vezes (em cinco salas) ou nunca (em três salas), sendo diminuto o número de salas (quatro) em que a sua utilização ocorria frequentemente. Nestas quatro salas, os registos referemse a atividades, histórias, estações do ano, dias específicos ou nomes das crianças, sendo que as crianças os observavam, dialogando sobre os mesmos com os colegas, relembrando o que já havia sido feito e fazendo tentativas de leitura dos mesmos registos.

É de assinalar ainda a existência de quadros para tarefas específicas, que fazem já parte das rotinas das salas observadas, como é o caso do quadro de presenças, utilizado diariamente, após o acolhimento e antes do início das tarefas do dia. No caso das salas de três anos, essa presença é assinalada pela educadora e pela criança no quadro onde se encontra registado o nome e a respetiva imagem de cada criança. No caso das salas de quatro e cinco anos, o registo de presença é efetuado pela criança ou colocando um círculo colorido (verde ou amarelo) ou uma cruz ou ainda escrevendo o respetivo nome. Dois outros quadros (o quadro do estado do tempo e dos aniversários) são ainda possíveis de encontrar na generalidade das salas observadas, quer nas salas de três anos (nas quais as crianças usam símbolos ou desenhos/imagens associadas ao estado do tempo ou ainda fotos, no caso do quadro dos aniversários) quer ainda na sala dos quatro e dos cinco anos (aqui recorrendo igualmente a imagens e, apenas numa sala dos quatro anos, ao nome da criança associado à sua imagem). A planificação de tarefas é outra das atividades em que as crianças são chamadas a colaborar, concretamente numa das salas dos quatro anos, identificando no quadro das responsabilidades, mediante colocação de uma sua foto, a área em que pretendem trabalhar. Em duas outras salas de quatro anos, as tarefas são planificadas por desenhos. Numa sala de cinco anos, foi ainda possível encontrar um outro quadro, de avaliação de tarefas, cujo preenchimento era feito conjuntamente e semanalmente pelo educador e pela criança, mediante a utilização de desenhos.

A existência de cadernos ou capas onde são compiladas as produções escritas das crianças foi assinalada em oito das salas observadas (uma de três anos, nas quatro de quatro anos e ainda em três de cinco anos). Os materiais existentes estão etiquetados recorrendo sobretudo à utilização conjunta de letras e imagens, sendo que a letra utilizada é sempre ou quase sempre a variante maiúscula de imprensa, habitualmente usada por implicar traços mais retos e cujo desenho é considerado mais ajustado ao nível de motricidade fina que as crianças em idade préescolar evidenciam.

Os "tempos mortos" são aproveitados para promover a leitura e escrita em nove das doze salas (em três das salas de três anos, em duas das de quatro anos e em três das de cinco anos), mas, curiosamente, só em quatro das salas (três das salas de três anos e uma das de quatro anos) há um momento na rotina diária que privilegia atividades específicas de leitura e escrita, geralmente associado à leitura de uma história em grupo e reconto e exploração da mesma.

O que parece possível concluir-se destes dados é que nas salas observadas de cinco anos, por exemplo, não foi possível observar, de forma sistemática, evidências de que estas salas se destacam claramente face às condições de organização e gestão do espaço físico e da rotina diária proporcionadas nas salas de quatro ou até dos três anos observadas. Esta indiferenciação pode ser encontrada também ao nível das práticas de leitura e de escrita, objeto de análise na última dimensão da grelha de Alves Martins \& Santos (2005). De facto, no trabalho com as crianças, as educadoras parecem valorizar as atividades de promoção da compreensão oral, promovendo frequentemente a leitura de livros de histórias, a partir dos quais realizam depois atividades orais de compreensão do texto e ensinam às crianças rimas ou lengalengas. Estas tarefas, sendo importantes para desenvolver o gosto e as competências de leitura, não são, por si só suficientes para assegurar a oportunidade para que as crianças construam hipóteses e reelaborem conceções acerca da funcionalidade e aspetos conceptuais da linguagem escrita, competências estas determinantes para o sucesso posterior na aprendizagem da leitura e da escrita. Ao contrário do que seria desejável, atendendo inclusive, ao que se encontra previsto nas Orientações Curriculares para a Educação Pré-Escolar (2016), as educadoras das salas observadas desvalorizam, ao nível da produção oral, as atividades em que se propõe à criança a criação de rimas e lengalengas ou o relato de histórias, bem como os jogos que apelam à reflexão sobre a linguagem oral ou escrita, atividades estas que foi possível observar com regularidade em apenas duas salas dos quatro anos e duas salas dos cinco anos. A capacidade de refletir sobre as unidades da linguagem oral (os sons) e a forma como estas se 
relacionam com as unidades da linguagem escrita (as letras), pode ser exponenciada mediante a promoção de atividades de consciência fonológica e que a criança é chamada a contar sílabas, identificar sílabas e sons iniciais, intermédias e finais comuns. De igual forma, a reduzida valorização da figura do educador como "escriba": as crianças são poucas vezes estimuladas a ditarem-lhe histórias, relatos ou outros tipos de texto, nem são frequentemente postas por escrito histórias, rimas ou lengalengas que as crianças conheçam. À exceção de três salas (uma sala de cinco anos e duas salas de quatro anos), a frequência de jogos que apelam à reflexão sobre a linguagem escrita é reduzida ou nula nem é frequente confrontar a escrita ou a leitura das crianças com a da educadora. Estas atividades constituiriam oportunidades para a criança ir descobrindo o princípio alfabético, assente na associação de que as letras representam os sons que pronunciamos num sistema de escrita alfabético como o nosso.

O reduzido nível de envolvimento das crianças, nomeadamente em situações em que seria desejável pedir a crianças que já têm alguns conhecimentos acerca da escrita para ajudarem as que estão a "despertar" (promovendo a autonomia e a cooperação entre pares), bem como o facto de não se incentivar, de forma sistemática, a que a criança procure palavras escritas nos elementos impressos da sala são outra das dimensões das práticas observadas que poderia ser alvo de melhoria.

\section{Considerações finais}

Os resultados mostram que, ainda que ao nível da organização e gestão do espaço físico e da rotina diária estejam previstos recursos e momentos para promover a leitura e escrita, as práticas observadas denotam a ausência de uma intencionalidade educativa subjacente a algumas atividades e ainda alguma falta de sistematicidade na promoção de outras atividades, que poderiam assegurar uma maior autonomia e níveis superiores de desenvolvimento literácito das crianças.

De facto, as educadoras de infância das salas observadas tendem a valorizar as atividades que destacam o uso oral da linguagem, em detrimento de um uso da vertente impressa. Quer ao nível da promoção da linguagem oral, quer sobretudo ao nível da linguagem escrita, são ainda pouco frequentes, na maioria das salas observadas, as situações que apelam a uma reflexão sobre aspetos da língua que a literatura desde há muito comprovou serem fatores determinantes para o sucesso na aprendizagem da leitura e da escrita.

Podemos assim concluir que a formação destas educadoras, supervisores da prática de ensino supervisionada, parece não refletir o estado de saber nesta área de aprendizagem e desenvolvimento da criança, pelo que esta constitui uma lacuna formativa a colmatar nomeadamente ao nível da formação contínua e pós-graduada.

É ainda de salientar a necessidade de oferecer, às estagiárias, modelos de educadores com práticas consistentes e regulares de promoção do conhecimento literácito, organizadas em torno de objetivos claros de desenvolvimento e aprendizagem de um conhecimento sólido sobre a linguagem e literacia.

\section{Referências}

Alves Martins, M. (1996). Pré-História da Aprendizagem da Leitura. Conhecimentos precoces sobre a funcionalidade da linguagem escrita, desenvolvimento metalinguístico e resultados em leitura no final do $1 .^{\circ}$ ano de escolaridade. Lisboa: ISPA.

Alves Martins, M. (2007). Literacy practices in kindergartens and conceptualizations about written language among Portuguese preschool children. L1Educational Studies in Language and Literature, 7 (3), 147-171.

Alves Martins, M. \& Santos, A. I. (2005). Avaliação das práticas de leitura e de escrita em Jardim de Infância. Revista do GEDEI Infância e Educação: investigação e práticas, 7, 59-69.

Fernandes, P.F. (2005). Concepções e Práticas de Literacia Emergente em Contexto de Jardim-deInfância. Dissertação de Doutoramento apresentada à Universidade do Minho, Portugal.

Ferreiro, E. (1990). Reflexões sobre Alfabetização, Porto Alegre: Artes Médicas.

Mata, L. (2008). A descoberta da escrita. Lisboa: Ministério da Educação/ DGIDC.

Ministério da Educação/DGIDC (2010). Metas de Aprendizagem. (Coordenação de Sim-Sim et al.). Disponível em http://metasdeaprendizagem.dge.mec.pt/metasdeapren dizagem.dge.mec.pt/educacao-preescolar/apresentacao/index.html

Santos, A. \& Alves Martins, M. (2014). Conceções dos educadores portugueses sobre a linguagem escrita: um estudo de caso. Revista de Estudios e Investigación en Psicología y Educación, 1 (1), 26-34.

Silva, I.L., Marques, L., Mata, L. \& Rosa, M. (2016) Orientações Curriculares para a Educação PréEscolar. Lisboa: Ministério da Educação/ DireçãoGeral da Educação. http://www.dge.mec.pt/ocepe/sites/default/files/Orient acoes_Curriculares.pdf

\section{Agradecimentos}

Este trabalho foi financiado por Fundos Nacionais através da FCT (Fundação para a Ciência e a Tecnologia) e cofinanciado pelo Fundo Europeu de Desenvolvimento Regional (FEDER) através do COMPETE 2020 Programa Operacional Competitividade e Internacionalização (POCI) no âmbito do CIEC (Centro de Investigação em Estudos da Criança da Universidade do Minho) com a referência POCI-01-0145-FEDER007562 . 